\title{
The Influence of Child Abuse Experience on School Adjustment: Serial Multiple Mediation Effects of Aggression, Peer Relations, Depression, and Self-Esteem
}

\author{
Young Ae Lee \\ Instructor, Graduate School of Education, Keimyung University, Daegu, Korea \\ 아동의 학대경험이 학교적응에 미치는 영향: 공격성, 또래관계, 우울 및 자아 \\ 존중감의 순차적 다중매개효과 \\ 이영애 \\ 계명대학교 교육대학원, 강사
}

Objectives: The aims of this study was to examine the serial multiple mediation effects of aggression, peer relations, depression and self-esteem on the impact between child abuse experience and school adjustment in late elementary school children.

Methods: This study was applied to assess second and third wave data from the Korean Children and Youth Panel Survey. The participants consisted of 2,312 fifth and sixth grade elementary school students (1,231 boys, 1,099 girls). The data were analyzed using serial multiple mediation model with PROCESS macro.

Results: First, aggression, peer relations, depression, and self-esteem had significant indirect effects on each other and on the association between child abuse experience and children's school adjustment. However, child abuse experience had no direct effects on children's school adjustment. The indirect effects of child abuse experience on aggression were largest among the four mediators. Second, aggression, peer relations, depression, and self-esteem were found to have serial multiple mediation effects on the relationship between child abuse experience and child's school adjustment. Conclusions: The results of this research showed that aggression, peer relations, depression, and self-esteem can be considered as multiple mediating variables on the association between child abuse experience and child's school adjustment.

Keywords: child abuse experience, aggression, peer relations, depression, self-esteem, school adjustment

\section{Introduction}

초기 애착으로 시작되는 부모-자녀 관계의 질은 발달과 적응 에 결정적이다. 부모가 자녀의 발달과 적응에 미치는 영향 가 운데 하나는 자녀를 다루고 관리하는 특정한 방식이다(Wood

Corresponding Author: Youngae Lee, Instructor, Graduate School of Education, Keimyung University, 1095, Dalgubeol-daero, Dalseo-gu, Daegu, Korea

E-mail: leevivian@hanmail.net et al., 2003). 즉, 부모의 양육방식은 부모의 자녀에 대한 태도 와 목표, 양육행동 패턴의 집합이라 할 수 있다. 그러나 주로 가정 내에서 부모나 보호자에 의해 발생하는 아동 학대는 부 모가 적절한 양육을 제공하는데 실패한 극단적인 형태라 할 수 있다. 아동학대 현황보고서(Ministry of Health and Welfare,

(C)The Korean Association of Child Studies

This is an Open Access article distributed under the terms of the Creative Commons Attribution Non-Commercial License (http:// creativecommons.org/licenses/by-nc/4.0) which permits unrestricted noncommercial use, distribution, and reproduction in any medium, provided the original work is properly cited. 
2018)에 의하면 2017년 아동보호전문기관으로 신고접수 된 사례 중 피해아동의 연령은 중학생에 해당하는 만 13-15세의 비율이 가장 높았고, 초등학교 고학년에 해당하는 만 10-12세 아동의 비율이 그 다음 이었다. 아동학대 발생 빈도의 경우, 일 주일에 한 번 이상 빈번하게 발생하는 비율이 높았는데 이러 한 학대 발생은 아동의 사회성, 행동문제에 부정적인 영향을 줄 가능성이 높기 때문에 일회성의 학대가 만성적인 학대로 이어지지 않도록 경미한 수준의 아동학대라도 재 학대 방지를 위한 체계적인 관리가 필요하다는 것을 강조하고 있다.

아동의 학대경험이 심리사회적 적응, 행동문제 및 사회적 유능성에 미치는 영향을 밝힌 여러 선행연구들을 통해(Stirling \& Amaya-Jackson, 2008) 학대를 경험한 아동과 청소년이 학 대경험이 없는 아동과 청소년에 비해, 그리고 지속적인 학대 경험이 일시적인 학대경험에 비해 우울, 비행, 공격성 및 외 현적 문제행동을 더 나타내는 것으로 밝히고 있다(Cho, Kim, \& Song, 2014; Éthier, Lemelin, \& Lacharité, 2004; S. J. Kim \& Chung, 2013; H. B. Lee, 2014; Moylan et al., 2010). 또, 아동의 학대경험은 낮은 자아존중감(H. S. An, 2014; Shen, 2009), 또 래관계의 문제(Bolger, Patterson, \& Kupersmidt, 1998) 그리고 아동기 이후 청소년기를 거쳐 성인기의 심리사회적 적응에 도 영향을 미치는 것으로 나타났다(Stirling \& Amaya-Jackson, 2008). 학대경험으로 인한 정서, 행동 상의 문제 중 특히 우울, 공격성 등의 내재화와 외현화 문제가 일관되게 보고되고 있다 (C. K. Kim \& Cho, 2014).

학령기 아동에게 있어서 학교적응은 중요한 과제이다. 학 령기 이후의 아동들은 생활중심이 가정에서 학교로 옮겨지게 된다. 학교는 학령기 아동의 지적 역량을 발달시키고 심리사 회적 적응과 관련된 유능감과 소속감을 경험하게 하며 부모 이외에 또래 및 교사와의 대인관계 경험의 기회를 제공하는 중요한 환경적 맥락으로, 학교적응은 아동과 청소년기에서 중 요한 발달과제 중의 하나로 강조되고 있다(Danielsen, Samdal, Hetland, \& Wold, 2009). 학교적응은 학생의 특성과 학습 환경 의 다차원적 특성 및 요구간의 교육적 적합성을 최대화하는데 필요한 학교에서의 순응(Spencer, 1999)으로 정의하였다. 한편, Moon (2002)은 학교적응을 학교생활과 밀접하게 관련된 학업 적 적응행동, 사회적 적응행동, 정의적 적응행동을 하위차원 으로, K. M. Lee와 Kim (2008)은 학교적응 척도를 학교 환경에 서 이루어지는 학업 및 친구, 교사, 그리고 학교생활의 네 가지 하위영역으로 구성하여 측정하였다. 이와 같이 학교적응에 관 한 개념적 정의는 학자들마다 상이한 측면이 있으나 전반적으 로 최근의 연구들은 학업성취나 학업수행 능력뿐만 아니라 학
교생활의 다양한 영역들을 고려하여 학교적응이라는 개념을 폭넓게 재구성하려는 경향을 보이고 있다(Shin \& Kim, 2014). 이에 따라 본 연구에서는 학교적응을 학습활동에 대한 흥미와 학업성취에 대한 가치와 추구 정도, 교사 및 친구와의 관계성 을 포함하는 개념으로 정의하고자 한다.

학교적응에 관련된 연구들은 주로 아동 및 청소년의 개인 요인, 가족관련 요인, 그리고 학교관련 요인을 중심으로 다양 하게 수행되었다. 이 중 학교적응에 영향을 미치는 가족관련 요인으로는 특히 부모에 의한 학대 및 부모의 양육태도 등이 제시되었다(D.-K. Kim \& Kim, 2015). 학교적응이 아동의 성 장과 발달에 미치는 영향에도 불구하고 가정에서 부모나 보 호자에 의한 학대는 강압적이고 처벌적인 양육방식으로 부모 와 자녀와의 관계에 심한 손상을 초래하여 아동의 심리사회적 발달과 학교적응에 어려움을 야기할 수 있다(S. Kim \& Chun, 2015). 아동의 학교적응 향상은 아동 자신의 유능감과 학교에 대한 소속감을 통해 긍정적 자아개념과 대인관계 능력을 촉진 하고 학대경험으로 인한 심리적 어려움으로 부터 아동을 보호 하고 성장과 발달을 도움으로써 이후의 심리사회적 적응의 기 반을 마련할 수 있다는 점에서 함께 고려할 필요가 있다.

학교적응과 아동의 학대경험에 관련된 선행연구들에 의 하면 학대경험은 학업능력과 학업 성취도의 저하(Shonk \& Cicchetti, 2001), 학교에서 또래관계의 형성 및 교사와의 관계 (H. Bae, 2010; Chung, 2008; Jo, 2012; H. G. Kim, 2014; M. Kim \& Park, 2004; S. Kim, Yim, \& Chung, 2014)에 직접적으로 영 향을 미치는 직접효과가 있었다. 이러한 기존의 선행연구들과 관련하여 학대경험과 학교적응의 관계에서 매개요인에 의한 영향력을 알아보기 위해 구조관계 및 매개효과 분석에 관한 연구들이 수행되었다.

한국아동청소년패널조사 자료를 사용하여 초등학교 4학 년에서 중학생을 대상으로 구조관계를 분석한 연구(S. Kim \& Chun, 2015; K.-W. Park, 2014)와 잠재성장모형을 적용한 종단 연구를 통해 학대 경험은 학교적응에 직접효과를 나타내지 않았고(H. J. An, 2016) 우울, 공격성, 자아존중감 및 또래관계 등과 부모양육태도, 부모자녀 관계 등 가정환경 요인을 통해 직접 혹은 간접효과가 유의한 것으로 나타났다(H. Bae, 2010; Chang \& Yang, 2007; H. G. Kim, 2014; J. Kim \& Song, 2014; A. Park, 2014; Y. J. Park \& Sung, 2014). 이들 매개요인 중 공격성, 또래관계, 우울 및 자아존중감은 아동의 학교적응에 영향을 미치는 위험요인 혹은 보호요인으로 분류되고 있다(Jo, 2012; S. Park \& Yoon, 2013). 이러한 선행연구 결과들을 통해 아동의 학대경험은 학교적응에 직접적으로 영향을 미칠 수도 있지만 
학대경험으로 인한 학교적응의 영향에 공격성, 또래관계, 우 울 및 자아존중감이 매개요인으로 작용함을 제시하고 있다. 그러나 기존의 선행연구들은 학령기 아동의 학대경험과 학교 적응의 관계에서 이들 매개변수 각각의 개별적인 매개효과 혹 은 구조관계를 파악하고자 한 연구들이 대부분으로 다중의 매 개변인 간 상호관련성을 경로분석을 통해 인과적 영향력을 살 펴본 연구는 이루어지지 않고 있다.

그러나 아동의 우울, 위축으로 대표되는 내재화 문제, 공격 성, 또래관계의 문제 및 자아존중감 간의 상호관련성에 대한 연구들을 통해 이들 변인들 간의 인과적 영향을 살펴보고자 한다. 먼저, 내재화 및 외현화 문제와 또래관계의 상호적 영향 을 밝히고자 한 연구들에 의하면(Bukowski, Laursen, \& Hoza, 2010; Hoglund \& Chisholm, 2014; Ladd, 2006; Lilienfeld, 2003; van Lier \& Koot, 2010) 5세에서 12세 아동과 학대경험 아동의 외현화 문제는 공격행동과 또래거부를, 위축행동과 또래거부 는 우울 등의 내재화 문제를 예측하는 것으로 밝히고 있다. 또 배척, 회피, 친구 없음의 또래관계 문제는 우울을 증가시켰으 나 시간의 흐름에 따른 또래관계의 형성은 우울의 변화를 조 절하는 것으로 보고되었다.

또 다른 선행연구들에서는 또래문제와 공격성은 내재 화 문제와 상호인과적 영향을 미치는 경로를 나타내었고 (Leadbeater \& Hoglund, 2009), 또래관계 문제는 공격성과 우 울을 매개하는 것으로 나타남(Morrow, Hubbard, McAuliffe, Rubin, \& Dearing, 2006)에 따라 공격성, 또래관계 문제, 우 울간의 상호인과적 관련성을 시사하고 있다. 이러한 연구들 과 더불어 아동의 학대경험에 대한 보호요인으로 또래관계 의 질과 자아존중감의 상호관련성을 분석한 연구(Bolger et al., 1998)에서는 지역사회에서 표집 된 학대경험 아동과 학대경 험이 없는 아동을 대상으로 잠재성장 모형을 적용하여 변화 양상을 탐색하였다. 그 결과 아동의 친밀한 상호적 또래관계 는 시간경과에 따라 학대경험 아동의 자아존중감 향상에 영향 을 미치는 것으로 나타남에 따라 또래관계의 질은 자아존중감 의 보호요인 역할을 하는 것으로 밝히고 있다.

다음, 아동의 학대경험과 또래관계, 자아존중감, 및 학교적 응의 관련성에 관한 연구들을 살펴보면 학대경험 아동이 모두 학교적응에 부정적인 영향을 받는 것은 아니라 하더라도 아동 의 학대경험, 부모의 처벌적 혹은 부정적인 양육행동은 학교 부 적응, 빈약한 또래 및 교사와의 관계(H. G. Kim \& Jo. 2016; Y. A. Lee \& Choi, 2015; Taussig \& Culhane, 2010)를 나타낸 한편 상호 적 또래관계와 또래애착을 형성한 아동은 학교부적응 수준이 낮은 것으로 나타났다(H.-J. Kim \& Hong, 2015; J.-I. Lee, Kim,
\& Han, 2014). 국내의 선행연구들 중 자아존중감은 아동의 학 대경험과 학교적응의 관계에서 부정적 영향을 완화하고 적응 적 수준을 강화하는 보호요인 중의 하나로 보고되었다(Kwon, Lee, \& Nho, 2013; A. Park, 2014; S. Park \& Yoon, 2013). 이러한 선행연구들을 통해 학령기 아동의 환경적 맥락에서 상호적 또 래관계, 또래와의 애착 형성은 아동의 부정적인 양육으로 인한 어려움을 완화하는 조절효과가 있다는 점에서 또래관계, 자아 존중감 그리고 학교적응의 상호관련성을 제시하고 있다.

지금까지 살펴본 선행연구에 대한 고찰을 토대로 공격성, 또래관계, 우울, 및 자아존중감은 학교적응에 영향을 미치는 매개변수로 공격성과 우울은 학령기 아동의 학교적응에 부정 적으로 작용하는 위험요인인 한편 또래관계와 자아존중감은 적응적 수준에 따라 조절효과를 나타내는 보호요인으로 작용 한다는 측면에서 이들 변수 간의 인과적 영향을 고려해볼 수 있다. 이론적으로 매개변수는 독립변수의 결과이며, 종속변수 의 원인이 된다(B. R. Bae, 2015). 예를 들어, 변수 $\mathrm{A}$ 는 변수 $\mathrm{B}$ 에, 변수 $\mathrm{B}$ 는 변수 $\mathrm{C}$ 에, 변수 $\mathrm{C}$ 는 변수 $\mathrm{D}$ 에 영향을 준다면 이들 변 수 간에 $\mathrm{A} \rightarrow \mathrm{B} \rightarrow \mathrm{C} \rightarrow \mathrm{D}$ 의 관계가 있기 때문에 학대경험은 매개 변수들인 공격성에, 공격성은 또래관계, 또래관계는 우울, 우 울은 자아존중감을 통해 학교적응에 영향을 미치는 매개적 경 로를 가정해 볼 수 있다.

따라서 본 연구의 목적은 학령후기 아동을 대상으로 학대경 험이 공격성, 또래관계, 우울, 자아존중감을 순차적으로 경유 하여 학교적응에 영향을 미치는 다중매개효과를 알아보고자 하는 데 있다. 이를 통해 학령후기 아동의 학교적응을 촉진하 고 부적응적 문제행동에 대한 상담적 개입 방안을 위한 기초적 인 자료와 정보제공을 할 수 있을 것이다. 연구문제는 다음과 같이 설정하였고 연구문제를 검정하기 위한 순차적 다중매개 모형은 Figure 1에 제시하였다.

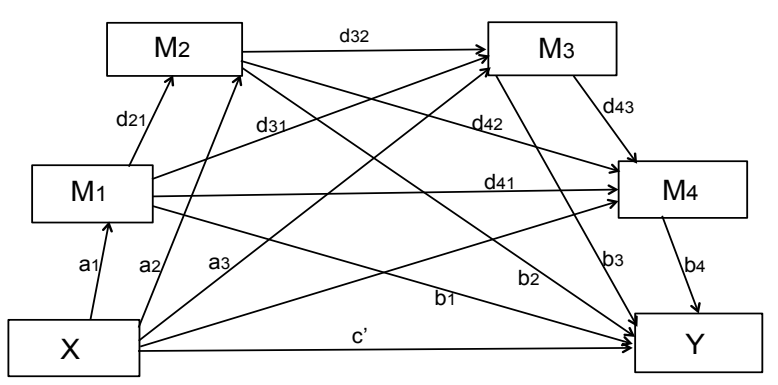

Figure 1. Serial multiple mediator model of aggression, peer relations, depression, and self-esteem in the association between abuse experience and school adjustment. $\mathrm{X}=$ abuse experience; $\mathrm{Y}$ = school adjustment; $\mathrm{M} 1$ = aggression; $\mathrm{M} 2$ = peer relations; $\mathrm{M} 3$ = depression; $\mathrm{M} 4$ = self-esteem; $\mathrm{a} 1 \sim \mathrm{d} 43$ = pathways. 


\section{연구문제 1.}

아동의 학대경험이 공격성, 또래관계, 우울 및 자아존중감 각 각을 통해 학교적응에 영향을 미치는 단순매개효과는 어떠한 가?

\section{연구문제 2.}

아동의 학대경험이 공격성, 또래관계, 우울 및 자아존중감을 순차적으로 경유하여 학교적응에 영향을 미치는 다중매개효 과는 어떠한가?

\section{Methods}

\section{분석자료 및 연구대상}

본 연구에서 사용한 자료는 한국아동청소년패널조사 초4 패 널의 2 차와 3 차 년도의 자료로, 학대경험과 학교적응은 2 차와 3 차 년도의 2 개년 자료를, 공격성, 또래관계, 우울, 자아존중 감은 3 차 년도 자료를 사용하였다. 초4 패널의 전체 조사자는 전국에서 표집 된 2,378명이었으나 학대 문항에 반응하지 않 은 결측치를 제외한 2,312 명 (남자 = 1,213 명; 여자 = 1,099명) 을 대상으로 하였다. 이들 대상자는 초등학교 5학년과 6학년 에 해당한다. 학령후기 아동을 대상자로 선정한 이유는 이 시 기가 인지와 정서의 변화, 또래관계 및 환경적 맥락에서 변화 가 일어나고 학업적 수행과 사회적 기술을 학습하는 발달과제 들을 수행해야하기 때문(Oh \& Shim, 2014)이다. 또, 전국 아 동학대 현황 보고서(Ministry of Health and Welfare, 2018)에 따 르면 피해 아동의 연령은 만 10-12세에서 높은 비율을 차지하 고 있고, 패널자료가 전국의 아동을 표본 조사하여 아동의 전 반적인 특성을 파악하는데 적합하기 때문이다.

\section{연구변인 및 척도}

\section{독립변수: 학대경험}

학대 척도는 정서학대, 신체학대 및 언어폭력 피해 경험 여부 를 측정하는 4개 문항으로 되어있다. 문항의 내용은 "내 몸에 멍이 들거나 상처가 남을 정도로 부모님(보호자)께서 나를 심 하게 대하신 적이 많다.", "나에게 심한 말이나 욕을 하신 적이 많다.” 등으로 되어 있다. 학대경험은 2 차와 3 차 년도의 2 개년 에 측정된 자료를 합산하여 점수의 범위는 8 점에서 32 점이다.
신뢰도(Cronbach's $\alpha$ )는 2차년도와 3차년도 각각 .812와 .844 이었다. 본 연구에서는 학대경험을 유형별로 구분하지 않았 고, 학대경험은 부모와 보호자로 부터 신체학대와 정서학대 및 언어폭력의 피해를 겪거나 직접적으로 당한 적이 있는 것 을 의미한다. 학대라는 용어는 아동학대, 아동 학대경험 혹은 피학대경험으로 혼용하여 사용하였다.

\section{종속변수: 학교적응}

학교적응 척도는 학습활동, 교우관계, 교사관계 및 학교규칙의 하위영역별 5 문항 씩 총 20 문항이다. 문항의 내용은 "놀이나 모둠활동을 할 때 친구들이 내 말을 잘 따라준다.” "우리 선생 님은 나에게 친절하시다.” 등으로 되어 있다. 학교적응은 2 차 와 3 차 년도의 2 개년에 측정된 자료를 합산하여 점수의 범위는 32 점에서 160 점이다. 점수가 높을수록 학습활동에 대한 흥미, 학교규칙의 준수, 교사 및 친구와의 관계성이 좋은 것을 의미 하며 학교적응 수준이 높은 것을 나타낸다. 신뢰도(Cronbach's $\alpha$ )는 2 차년도와 3 차년도 각각 .891과 .889이었다.

매개변인: 공격성, 또래관계, 우울, 자아존중감

공격성 척도는 6 문항으로 문항의 내용은 "내가 원하는 것을 못하게 하면 따지거나 덤빈다.” 등으로 구성되어 있다. 점수 의 범위는 6점에서 24점이며 신뢰도(Cronbach's $\alpha$ )는 .836이 었다. 또래관계에 대한 측정은 의사소통, 신뢰, 소외의 하위영 역별 3 문항씩 총 9 문항으로 되어있는 또래애착 척도를 사용하 였다. 문항의 내용은 "나는 내 친구들에게 내 고민과 문제를 이 야기 한다.", "친구들은 내가 요즘 어떻게 지내는지 잘 모른다." 등으로 되어 있다. 점수의 범위는 9점에서 36점이며 신뢰도 (Cronbach's $\alpha$ )는 .784이었다. 전체 문항을 합산하여 점수가 높 을수록 또래관계가 좋음을 나타낸다.

우울 척도는 10 문항으로 문항의 내용은 “모든 일이 힘들 다.”, “울기를 잘 한다.”, “장래가 희망적이지 않다.” 등으로 구성되어 있다. 점수의 범위는 10 점에서 40 점이며 신뢰도 (Cronbach's $\alpha$ )는 .922이었다. 자아존중감은 10문항으로 문항 의 내용은 "나는 내가 장점이 많다고 느낀다.", "나는 나에 대 해 긍정적인 태도를 지니고 있다.” 등으로 구성되어 있다. 점 수의 범위는 10 점에서 40 점이며, 신뢰도(Cronbach's $\alpha$ )는 .794 이었다.

본 연구에서 선정한 변수들을 측정한 척도들은 매우 그렇 다(1점), 그런 편이다(2점), 그렇지 않다(3점), 전혀 그렇지 않 
다(4점)로 평정하였으며(National Youth Policy Institute, 2017), 본 연구문제의 검정에 적합하게 점수를 역환산하여 사용하였 다.

\section{연구 모형}

본 연구문제를 검정하기 위해 학대경험(독립변수)이 공격성 (매개변수 1), 또래관계(매개변수 2), 우울(매개변수 3), 자아 존중감(매개변수 4 )을 순차적으로 경유하여 학교적응(종속 변수)에 영향을 미치는 순차적 다중매개모형을 설정하였다 (Figure 1). Hayes (2013)는 매개 및 조절, 조절된 매개모형을 분석할 수 있는 PROCESS macro를 개발하여 제시하였는데 본 연구의 모형은 6번에 해당한다. 이 모형에는 독립변수 $\rightarrow$ 매개변수 $\rightarrow$ 종속변수의 15 개 경로가 포함되어 있다. 하나의 매개변수를 경유하는 경로는 4개로 이들 경로의 간접효과는 $a_{1} b_{1}, a_{2} b_{2}, a_{3} b_{3}, a_{4} b_{4}$ 로 산출된다. 두개의 매개변수를 경유하는 경로는 6 개로 이들 경로의 간접효과는 $\mathrm{a}_{1} \mathrm{~d}_{21} \mathrm{~b}_{2}, \mathrm{a}_{1} \mathrm{~d}_{31} \mathrm{~b}_{3}, \mathrm{a}_{1} \mathrm{~d}_{41} \mathrm{~b}_{4,}$, $\mathrm{a}_{2} \mathrm{~d}_{32} \mathrm{~b}_{3}, \mathrm{a}_{2} \mathrm{~d}_{42} \mathrm{~b}_{4}, \mathrm{a}_{3} \mathrm{~d}_{43} \mathrm{~b}_{4}$ 로 분석된다. 세 개의 매개변수를 경유하 는 경로는 4 개로 이들 경로의 간접효과는 $\mathrm{a}_{1} \mathrm{~d}_{21} \mathrm{~d}_{32} \mathrm{~b}_{3}, \mathrm{a}_{1} \mathrm{~d}_{21} \mathrm{~d}_{42} \mathrm{~b}_{4}$, $\mathrm{a}_{1} \mathrm{~d}_{31} \mathrm{~d}_{43} \mathrm{~b}_{4}, \mathrm{a}_{2} \mathrm{~d}_{32} \mathrm{~d}_{43} \mathrm{~b}_{4}$ 이다. 4 개의 매개변수들을 연속적으로 모두 경유하는 1 개의 순차적 다중매개 경로의 간접효과는 $\mathrm{a}_{1} \mathrm{~d}_{21} \mathrm{~d}_{32} \mathrm{~d}_{43} \mathrm{~b}_{4}$ 로 측정된다. 그리고 학대경험에서 학교적응의 경 로가 설정되었고 직접효과((c')를 나타낸다.

\section{연구 절차 및 분석 방법}

본 연구모형은 매개변수들 간의 순차적인 인과적 영향력을 알 아보기 위한 횡단연구이다. 이에 따라 한국아동청소년패널조 사의 초 4 패널자료 중 본 연구모형에서 설정한 변수들이 조사 된 2차 년도(2011년)와 3차 년도(2012년)의 2개년 자료를 변 수 별로 합산하여 분석하였다. 먼저, 모든 변수들의 척도에 대 한 신뢰도(Cronbach's $\alpha$ )를 산출한 다음 변수들의 평균, 표준편 차, 왜도 및 첨도를 확인하고 상관 계수를 산출하였다. 둘째, 최소자승(ordinary least square) 회귀분석을 통해 변수들 간 영 향력을 확인하였다. 셋째, 하나의 매개변수만 통과하는 단순 매개와 두 개 이상의 매개변수를 경유하는 순차적 다중매개의 15 개 경로들에 대한 특정 간접효과(specific indirect effects)를 분 해하였다. 기술통계와 상관계수의 산출, 회귀분석 및 간접효 과의 유의성 검정은 붓스트랩(bootstrap) $95 \%$ 신뢰구간 설정 방법을 사용하였다. 붓스트랩 표본 수는 10,000 개로 지정하였 다. 순차적 다중매개효과 분석에는 PROCESS macro (Hayes,
2013)와 SPSS 21 (IBM Co., Armonk, NY)을 사용하였다.

\section{Results}

\section{변수들의 기술통계 및 상관}

연구 모형에 관련된 변수들의 평균, 표준편차, 왜도 및 첨도와 상관계수는 Table 1 에 제시하였다. 모든 변수들의 왜도 및 첨 도의 절대 값이 각각 2 미만과 4 미만으로 $(H$. B. Lee, 2014) 정 규분포 가정을 충족하였다. 주요 변수들은 학대경험과 공격성 $(r=.335)$, 학대경험과 우울 $(r=.308)$ 간 에는 정적 상관을, 그 리고 학대경험과 또래관계 $(r=-.259)$ 및 학대경험과 자아존중 감 $(r=-.345)$, 학대경험과 학교적응 $(r=-.241)$ 간 에는 부적 상 관을 나타내었으며 $95 \%$ 신뢰구간에서 통계적으로 유의하였 다 $(p<.01)$.

\section{순차적 다중매개모형의 회귀분석 결과}

매개효과를 검정하기에 앞서 종속변수의 자기상관과 확인하 고 독립변수와 매개변수의 다중공선성을 검토하였다. 종속변 수의 자기상관을 나타내는 Durbin-Watson 지수는 $1.888(1.8$ $<\mathrm{d}<2.22)$ 로 2 미만이어서 자기상관이 없음에 따라 독립적이 라고 할 수 있다. 변수들의 다중공선성을 검토하는 VIF값은 학대경험이 1.238 , 우울은 1.433 , 공격성은 1.400 , 또래관계는 1.451 , 자아존중감은 1.571 로 10 미만이어서 다중공선성의 문 제가 없는 것으로 판정하였다.

다음, 순차적 매개효과를 분석하기 위해 최소자승 경로분 석을 이용한 회귀분석 결과는 Table 2와 Figure 2에 제시하였 다. 매개변수인 공격성, 또래관계, 우울 및 자아존중감에 대한 회귀분석 결과를 살펴보면 공격성은 또래관계 $\left(\mathrm{d}_{21}=-.165, p<\right.$ $.001)$ 에 부적으로, 우울 $\left(\mathrm{d}_{31}=.703, p<.001\right)$ 에는 정적으로 유의 한 영향을 나타내었다. 그리고 또래관계는 우울 $\left(\mathrm{d}_{32}=-.164, p\right.$ <.001) 그리고 우울은 자아존중감 $\left(\mathrm{d}_{43}=-.120, p<.001\right)$ 에 부적 으로, 자아존중감 $\left(\mathrm{d}_{42}=.476, p<.05\right)$ 에 정적으로 유의한 영향 을 나타내었다. 자아존중감은 공격성 $\left(\mathrm{d}_{41}=-.033, p>.05\right)$ 에 유 의하게 영향을 미치지 않았다. 
Table 1

Descriptive Statistics of Variables and Correlations

\begin{tabular}{|c|c|c|c|c|c|c|}
\hline & 1 & 2 & 3 & 4 & 5 & 6 \\
\hline 1. Abuse experience & - & & & & & \\
\hline 2. Aggression & $.335^{* *}$ & - & & & & \\
\hline 3. Peer-relations & $-.259^{* *}$ & $-.204^{* *}$ & - & & & \\
\hline 4. Depression & $.308^{* *}$ & $.496^{* *}$ & $-.246^{* *}$ & - & & \\
\hline 5. Self-esteem & $-.345^{* *}$ & $-.263^{* *}$ & $.557^{* *}$ & $-.345^{* *}$ & - & \\
\hline 6. School adjustment & $-.241^{* * *}$ & $.318^{* *}$ & $.426^{* *}$ & $-.296^{* *}$ & $.493^{* *}$ & - \\
\hline$M$ & 13.766 & 12.178 & 27.271 & 17.003 & 28.149 & 121.378 \\
\hline$S D$ & 4.361 & 3.664 & 4.559 & 6.039 & 4.549 & 14.982 \\
\hline Skewness & .959 & .256 & -.170 & .729 & -.181 & -.387 \\
\hline Kurtosis & .982 & .113 & .120 & .221 & -.114 & .974 \\
\hline
\end{tabular}

Note. $N=2,171$ (bootstrap sample).

${ }^{* *} p<.01{ }^{* * *} p<.001$.

Table 2

Results of a Regression Analysis Among the Multiple Mediating Variables, Independent Variable, and Dependent Variable

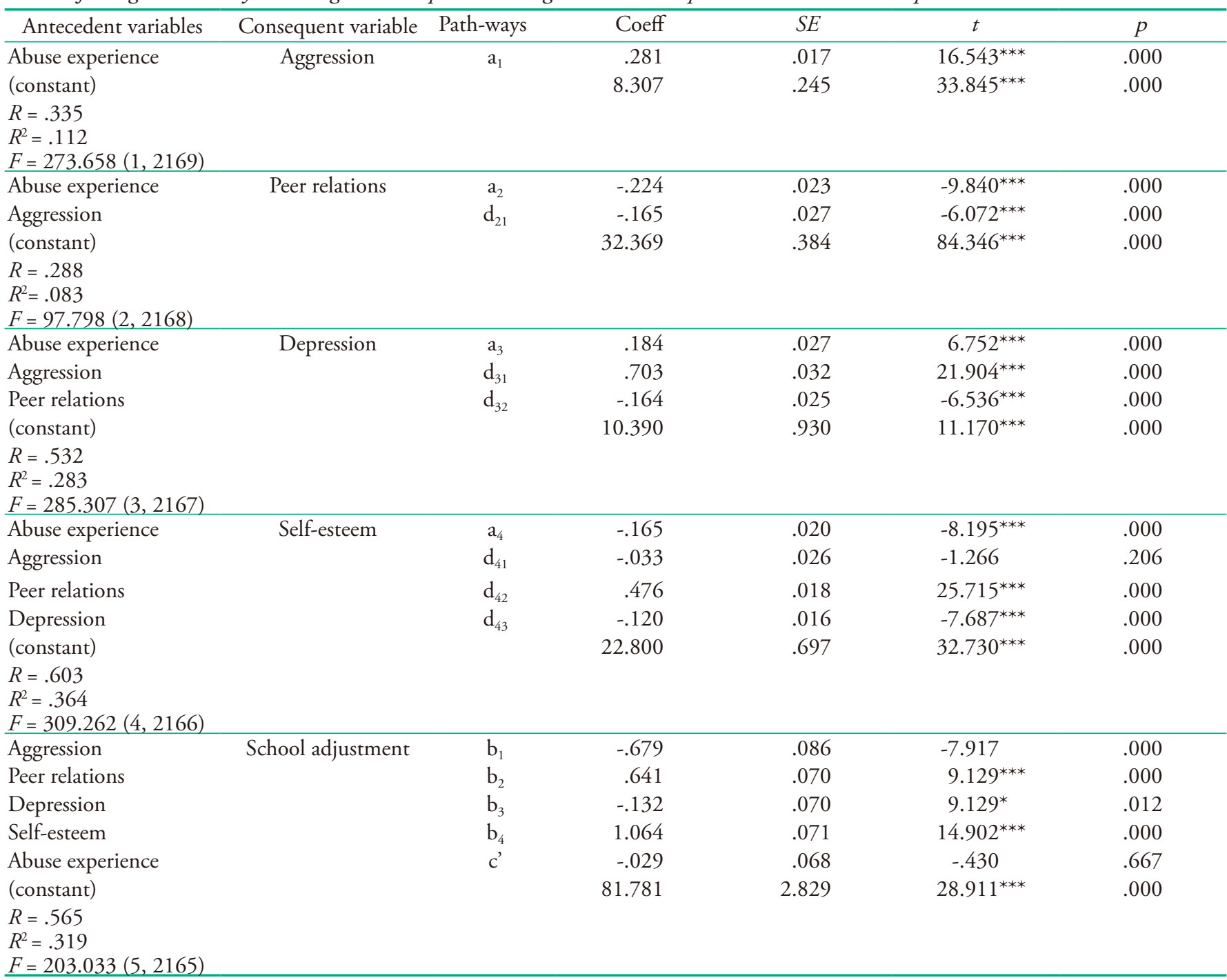

Note. Coeff $=$ Non-standardized coefficient.

${ }^{*} p<.05 .{ }^{* * *} p<.001$. 


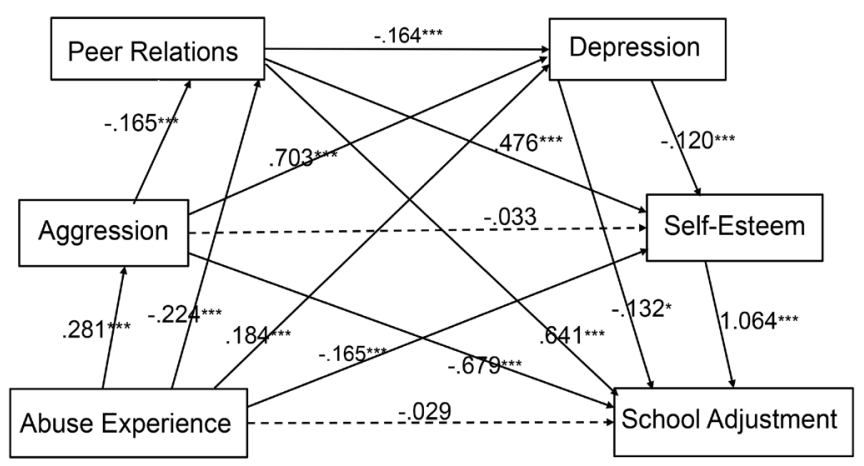

Figure 2. Results of regression analysis among the multiple mediating variables, independent variable, and dependent variable. Coefficients are non-standardized. The dotted line indicates a nonsignificant pathway.

${ }^{*} p<.05 .{ }^{* * *} p<.001$.

\section{다중매개변수의 간접효과 분해 결과}

4 개의 매개변수들에 의한 15 개 경로들의 간접효과에 대한 결 과는 다음과 같다.

매개변수 하나와 두개를 경유하는 경로들의 간접 효과

매개변수 하나와 두 개를 통한 경로들의 간접효과에 대한 결 과는 Table 3에 제시하였다. 먼저, 하나의 매개변수를 경유하 는 4 개 경로들의 간접효과는 공격성 $\left(\mathrm{a}_{1} \mathrm{~b}_{1}=-.191\right)$, 또래관계 $\left(\mathrm{a}_{2} \mathrm{~b}_{2}=-.144\right)$, 우울 $\left(\mathrm{a}_{3} \mathrm{~b}_{3}=-.024\right)$, 자아존중감 $\left(\mathrm{a}_{4} \mathrm{~b}_{4}=-.175\right)$ 모두 음의 값을 나타내었다. 이들 간접효과는 $95 \%$ 신뢰구간에 0 을 포함하고 있지 않기 때문에 통계적으로 유의하였다. 이들 간
접효과의 크기는 공격성이 가장 큰 것으로 나타났다. 또, 각각 의 매개변수들은 단순매개효과를 나타내어 학대경험은 공격 성, 우울, 또래관계, 자아존중감 각각을 통해 학교적응에 부적 으로 영향을 미친다고 할 수 있다.

두 개의 매개변수를 경유하는 6 개 경로의 간접효과는 공격 성과 또래관계 $\left(\mathrm{a}_{1} \mathrm{~d}_{21} \mathrm{~b}_{2}=-.030\right)$, 공격성과 우울 $\left(\mathrm{a}_{1} \mathrm{~d}_{31} \mathrm{~b}_{3}=-.026\right)$, 또래관계와 우울 $\left(\mathrm{a}_{2} \mathrm{~d}_{32} \mathrm{~b}_{3}=-.005\right)$, 또래관계와 우울 $\left(\mathrm{a}_{2} \mathrm{~d}_{42} \mathrm{~b}_{4}=\right.$ -.114), 우울과 자아존중감 $\left(\mathrm{a}_{3} \mathrm{~d}_{43} \mathrm{~b}_{4}=-.024\right)$ 이 모두 음의 값을 나 타내었으며 이들 간접효과는 $95 \%$ 신뢰구간에 0 을 포함하고 있지 않기 때문에 통계적으로 유의하였다. 6 개 경로 중 음의 간접효과가 가장 큰 것은 또래관계, 자아존중감을 통한 경로 이었다. 공격성과 자아존중감 $\left(\mathrm{a}_{1} \mathrm{~d}_{41} \mathrm{~b}_{4}=-.010\right)$ 을 통한 경로의 간접효과는 $95 \%$ 신뢰구간에 0 을 포함하고 있기 때문에 통계 적으로 유의하지 않았다.

매개변수 세 개와 네 개를 경유하는 경로들의 간 접효과

매개변수 세 개와 네 개를 경유하는 경로들의 간접효과에 대 한 결과는 Table 4에 제시하였다. 먼저, 세 개의 매개변수를 경 유하는 4 개 경로의 간접효과는 공격성, 또래관계와 자아존중 감 $\left(\mathrm{a}_{1} \mathrm{~d}_{21} \mathrm{~d}_{42} \mathrm{~b}_{4}=-.023\right)$, 공격성, 우울과 자아존중감 $\left(\mathrm{a}_{1} \mathrm{~d}_{31} \mathrm{~d}_{43} \mathrm{~b}_{4}=\right.$ -.025) 그리고 또래관계, 우울과 자아존중감 $\left(\mathrm{a}_{2} \mathrm{~d}_{32} \mathrm{~d}_{43} \mathrm{~b}_{4}=-.005\right)$ 은 음의 값을 나타내었으며 $95 \%$ 신뢰구간에 0을 포함하고 있지 않기 때문에 통계적으로 유의하였다. 공격성, 또래관계와 우 울 $\left(\mathrm{a}_{1} \mathrm{~d}_{21} \mathrm{~d}_{32} \mathrm{~b}_{3}=-.007\right)$ 은 $95 \%$ 신뢰구간에 0을 포함하고 있기 때

Table 3

The Indirect Effect of Pathways Through One and Two Mediating Variables

$95 \% \mathrm{CI}$

\begin{tabular}{|c|c|c|c|c|}
\hline & Effect & Boot $S E$ & Boot LLCI & Boot ULC \\
\hline Abuse experience $\rightarrow$ Aggression $\rightarrow$ School adjustment $\left(a_{1} b_{1}\right)$ & -.191 & .031 & -.255 & -.132 \\
\hline Abuse experience $\rightarrow$ Peer relations $\rightarrow$ School adjustment $\left(a_{2} b_{2}\right)$ & -.144 & .023 & -.195 & -.103 \\
\hline Abuse experience $\rightarrow$ Depression $\rightarrow$ School adjustment $\left(a_{3} b_{3}\right)$ & -.024 & .012 & -.051 & -.003 \\
\hline Abuse experience $\rightarrow$ Self-esteem $\rightarrow$ School adjustment $\left(\mathrm{a}_{4} \mathrm{~b}_{4}\right)$ & -.175 & .028 & -.233 & -.126 \\
\hline Abuse experience $\rightarrow$ Aggression $\rightarrow$ Peer relations $\rightarrow$ School adjustment $\left(a_{1} d_{21} b_{2}\right)$ & -.030 & .006 & -.044 & -.018 \\
\hline Abuse experience $\rightarrow$ Aggression $\rightarrow$ Depression $\rightarrow$ School adjustment $\left(a_{1} d_{31} b_{3}\right)$ & -.026 & .012 & -.051 & -.003 \\
\hline Abuse experience $\rightarrow$ Aggression $\rightarrow$ Self-esteem $\rightarrow$ School adjustment $\left(\mathrm{a}_{1} \mathrm{~d}_{41} \mathrm{~b}_{4}\right)$ & -.010 & .008 & -.027 & .006 \\
\hline Abuse experience $\rightarrow$ Peer relations $\rightarrow$ Depression $\rightarrow$ School adjustment $\left(a_{2} d_{32} b_{3}\right)$ & -.005 & .003 & -.011 & -.001 \\
\hline Abuse experience $\rightarrow$ Peer relations $\rightarrow$ Self-esteem $\rightarrow$ School adjustment $\left(\mathrm{a}_{2} \mathrm{~d}_{42} \mathrm{~b}_{4}\right)$ & -.114 & .015 & -.145 & -.087 \\
\hline Abuse experience $\rightarrow$ Depression $\rightarrow$ Self-esteem $\rightarrow$ School adjustment $\left(\mathrm{a}_{3} \mathrm{~d}_{43} \mathrm{~b}_{4}\right)$ & -.024 & .006 & -.037 & -.014 \\
\hline
\end{tabular}

Note. CI = bootstrap confidence interval; Boot LLCI = bootstrap lower limit; Boot ULCI = bootstrap upper limit. 
Table 4

The Indirect Effect of Pathways Through Three and Four Mediating Variables

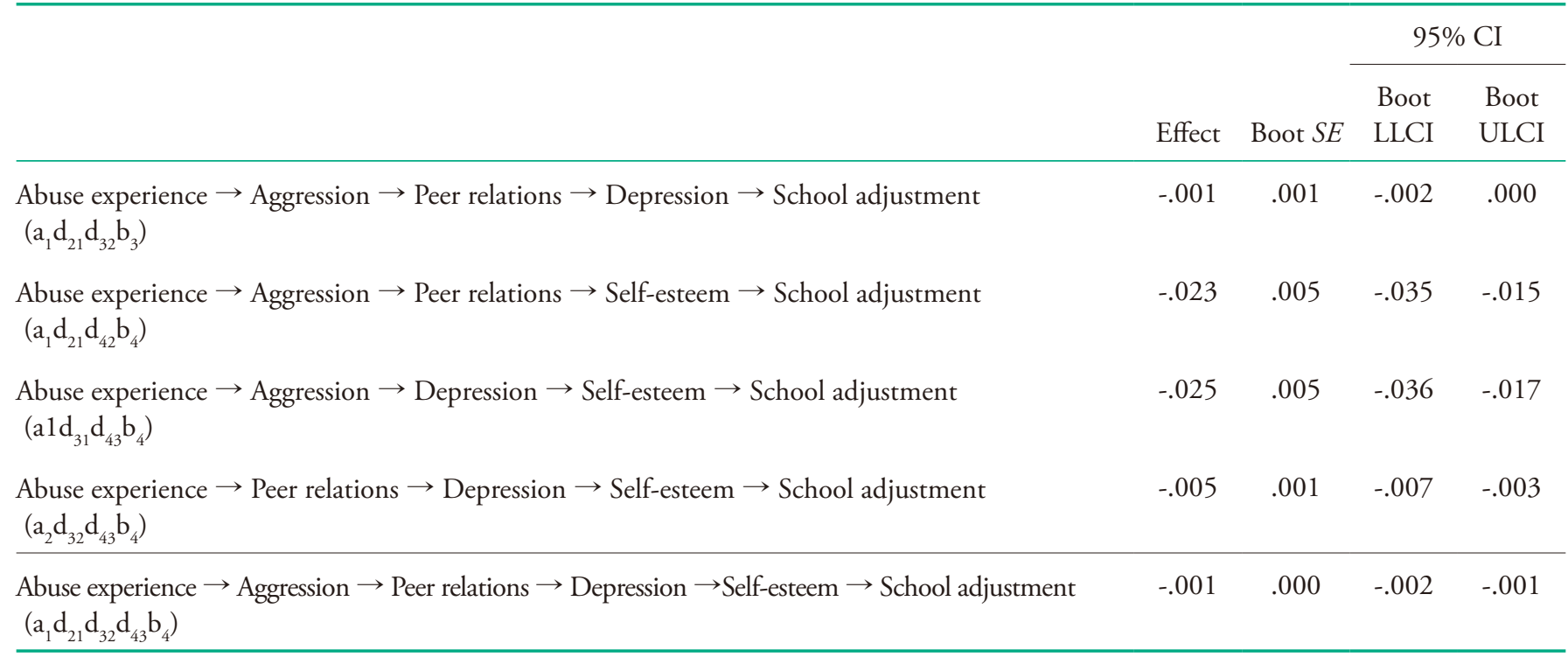

Note. CI = bootstrap confidence interval; Boot LLCI = bootstrap lower limit; Boot ULCI = bootstrap upper limit.

문에 통계적으로 유의하지 않았다. 다음, 네 개의 매개변수를 순차적으로 경유는 경로인 학대경험 $\rightarrow$ 공격성 $\rightarrow$ 또래관계 $\rightarrow$ 우 울 $\rightarrow$ 자아존중감 $\rightarrow$ 학교적응 $\left(\mathrm{a}_{1} \mathrm{~d}_{21} \mathrm{~d}_{32} \mathrm{~d}_{43} \mathrm{~b}_{4}=-.001\right)$ 의 간접효과 는 음의 값을 나타내었고, $95 \%$ 신뢰구간에 0 을 포함하고 있 지 않기 때문에 통계적으로 유의하였다. 즉, 학대경험은 우울, 공격성, 또래관계, 자아존중감을 연속적으로 경유하여 학교적 응에 간접적으로 영향을 미치는 것으로 나타남에 따라 이들 매 개변수는 순차적으로 인과적 영향을 미친다고 할 수 있다. 총 간접효과는 모든 특정 간접효과들의 합계이다. 총 간접효과는 -.798 이었고 $95 \%$ 신뢰구간(하한값: -.897, 상한값: -.699)에 0 을 포함하고 있지 않기 때문에 통계적으로 유의하였다.

\section{Discussion}

본 연구는 학령후기 아동을 대상으로 학대경험이 공격성, 또 래관계, 우울, 자아존중감의 다중매개변수를 순차적으로 경유 하여 학교적응에 영향을 미치는 다중매개효과와 매개변수 별 단순매개효과를 분석하여 인과적 영향을 알아보기 위한 것이 다. 본 연구를 통해 얻은 주요 연구결과들을 논의하면 다음과 같다.

첫째, 학대경험이 공격성, 또래관계, 우울, 자아존중감의 각 각 하나의 매개변수를 통해 학교적응에 미치는 간접효과는 부적으로 유의한 단순 매개효과를 나타내었다. 이들 매개변수
중 공격성의 간접효과가 가장 큰 것으로 나타났고, 학대경험 이 학교적응에 미치는 직접효과는 유의하지 않았다. 먼저, 공 격성, 우울은 학대경험으로 인한 학교적응의 영향에 매개효 과를 나타낸 본 결과는 아동의 학대경험은 학교적응에 직접 효과를 나타내지 않았고 우울 등의 내재화 문제와 공격성 등 의 외현화 문제는 학교적응에 매개효과를 나타난 선행연구 결 과들을 지지하였다(S. Kim \& Chun, 2015; S. J. Kim \& Chung, 2013; Shonk \& Cicchetti, 2001). 다음, 본 결과 중 또래관계, 자 아존중감은 각각 매개효과를 나타내었는데 부모의 학대 및 방 임이 학령기 아동의 학교적응에 미치는 영향에서 또래관계 와 또래애착(Hwang \& Kim, 2018; E. A. Kim \& Bae, 2016; H. G. Kim \& Jo, 2016) 또는 학교 내 주요 대인관계인 교우관계(S. Kim, Yim, \& Chung, 2014), 자아존중감(H. S. An, 2014; S. Park $\&$ Yoon, 2013)의 매개효과를 밝힌 결과들과 맥락을 같이 한다. 이들 결과를 통해 본 연구에서 선정한 공격성, 또래관계, 우울, 자아존중감은 학대경험과 학교적응의 관계에 작용하는 매개 요인들임을 알 수 있으며 공격성, 우울은 학교적응에 부정적 영향을 미치는 위험요인으로 작용하는 반면 상호적 또래관계, 긍정적 자아존중감은 학교적응 향상에 기여하는 보호요인으 로 작용할 수 있음을 시사한다.

또, 매개변수 중 공격성의 간접효과가 가장 큰 것으로 나타 난 본 결과는 부모의 처벌적 양육행동이 공격성에 미치는 영 향력이 형제관계 및 부모 간 갈등에 비해 상대적으로 큰 것으 로 나타난 결과(M. J. Kim \& Doh, 2001)와 관련된다. 한국복지 
패널 자료를 분석하여 초등학교 4학년에서 6학년 아동의 학 대경험이 공격성에 미치는 최신 효과는 유의하였으나 중학교 와 고등학교로 갈수록 최신 효과는 유의하지 않았던 결과(S. J. Kim \& Chung, 2013)와도 유사한 면이 있다. 이러한 결과에 대 해 학대는 부모와 자녀간의 안정되고 일관성 있는 관계의 손 상으로 부모-아동 사이의 강압적 상호작용 방식으로 인해 아 동은 자신의 감정이나 정서를 조절하고 사회정서적 경험을 표 현하는 것에 대한 어려움으로 공격적 행동을 표출하는 것으로 유추해볼 수 있다.

또한 우리나라의 경우 학대 발생은 학령후기인 초등학교 고학년에서 중학교 시기에서 발생 비율이 높은 추세를 보이고 있다. 아동기에서 청소년기로 전이되는 시기에 발달과정 상의 급격한 변화, 상급학교 진학에 요구되는 학업 수행에 대한 기 대 등이 아동과 가족에게 스트레스와 가족 갈등을 야기하여 아동학대의 가능성을 높여(S. Kim \& Lee, 2010) 공격성을 유발 할 수 있는 상황에 노출될 수 있을 것으로 사료된다. 특히, 학 령후기 아동기에 야기되는 공격성은 청소년기의 일탈행동이 나 비행 문제를 야기할 수 있기 때문에 교실 장면이나 또래 간 에서 공격적 행동을 나타내는 아동들에 대해 학대경험 여부를 점검하고 학대를 경험한 것이 나타나는 경우 상담적 접근과 재발생 방지를 위한 조치가 수반되어야 한다.

둘째, 학대경험이 공격성, 또래관계, 우울과 자아존중감을 순차적으로 경유하여 학교적응에 간접적으로 영향을 미치는 다중매개효과를 나타내었는데 이들 매개변인은 연속적으로 학교적응에 인과적 영향을 미치는 것을 의미한다. 이러한 결 과는 아동과 청소년의 학대경험과 학교적응의 관계에서 공 격성, 우울이 매개변수로 작용하고, 부모에 의한 피학대경험 은 학교적응에 직접효과를 나타내지 않는 것으로 보고한 결 과를 지지하였다(Chung 2008; E. J. Park \& Choi, 2014; K. W. Park, 2014; Y. J. Park \& Sung, 2014; You, 2014). 학대경험 아동 의 부모-자녀관계는 우울, 공격성과 유의한 관계가 있으며 학 교적응 및 학업 수행에 어려움을 겪는다는 연구결과(Chang \& Yang, 2007; Shonk \& Cicchetti, 2001)와도 관련지을 수 있다.

학대경험과 또래관계 및 자아존중감의 인과적 영향에 대한 본 결과를 Bolger 등(1998)의 결과를 토대로 논의하고자 한다. 이들의 연구에서 학대경험 아동은 학대경험이 없는 아동과 비 교해서 또래들이 덜 선호하였고, 학대경험 아동 중 일부에서 좋은 친구관계는 시간경과에 따라 자존감의 향상을 촉진하여 또래관계가 자아존중감을 높이는 조절변수로 확인된 결과는 본 결과와 맥락을 같이 한다. 이러한 측면에서 또래관계의 질 은 학대경험과 자아존중감의 관계를 조절하는 강화인자의 역
할을 한다. 그러나 이들의 연구는 학대경험을 종단적 연구방 법을 적용하였다는 점, 또래관계의 특성과 경험을 또래선호 도, 친구 수 및 친구와의 갈등으로 분류한 척도에 의한 결과라 는 점을 고려하여 해석되어야 한다. 이러한 연구결과에 대한 논의를 토대로 실천적 함의를 도출해보면 학교적응을 보다 더 촉진하기 위해 공격성, 우울을 다루는데 있어 보호요인으로 작용할 수 있는 또래관계와 자아존중감을 함께 고려한 자존감 향상 프로그램, 갈등해결 능력 향상을 위한 대인관계촉진 프 로그램, 자신과 타자와 교감하는 정서적 공감 훈련, 사회성 향 상을 위한 또래집단 간 체험활동의 기회 제공을 고려해 볼 수 있다. 이러한 접근은 교사, 학부모, 아동을 포함하는 다중체계 적 개입을 통해 학교적응 수준을 보다 더 높이고 아동의 지속 적인 성장과 발달을 촉진할 수 있을 것이다.

셋째, 학대경험이 공격성, 자아존중감을 통해 학교적응에 미치는 간접효과는 유의하지 않는 것으로 나타났는데 일부 선 행연구들에 의하면 아동과 청소년의 부모에 의한 학대가 공격 성에 영향을 미치는데 있어 자아존중감의 매개효과를 밝히고 있으며(GhorbaniAmir \& AhmadiGatab, 2011; J.-C. Kim \& Choi, 2011; Soler, Kirchner, Paretilla, \& Forns, 2013), 학대경험은 자아 존중감을 통해 공격성에 영향을 미치는 매개효과를 나타낸 결 과(S.-J. Lee \& Nam, 2016)들과 불일치한다. 이들의 연구는 신 체학대, 정서적 학대 및 방임 등으로 학대 유형을 구분하여 매 개효과를 분석하였으나 본 연구에서는 학대 유형 별로 구분하 지 않았다는 것, 대상자의 연령, 발달 시기 및 선정한 결과변인 이 다르다는 점에서 기인한 것으로 볼 수 있다. 학대경험은 연 구자나 연구방법에 따라 대상자의 학대발생 연령, 학대유형, 심각성 및 지속성 정도에 대한 평가와 개념이 상이할 뿐만 아 니라 학대가 발생한 시기에 따라 아동 및 청소년의 발달과제 수행 및 적응적 문제에 서로 다른 결과를 나타날 수 있다는 점 을 고려할 필요가 있다. 넷째, 학대경험이 공격성, 또래관계, 우 울을 통해 학교적응에 영향을 미치는 경로의 간접효과는 유의 하지 않았으나 우울, 또래관계 경로의 간접효과는 유의한 것으 로 나타난 본 연구결과를 함께 관련지어 논의하고자 한다. 그러 나학대경험과 공격성, 또래관계, 우울의 순차적인 인과적 영향 을 살펴본 선행연구가 이루어지지 않아 아동의 발달과 정신병 리에서 또래관계가 위험요인 혹은 보호요인으로 작용하는 기 제를 밝히고자 한 선행연구들을 통해 논의하고자 한다.

Bukowski 등(2010)은 3학년에서 5학년 아동을 대상으로 3차 시기에 걸친 종단연구를 통해 1 차시기에 배척과 회피의 또래 관계 문제는 3 차시기의 우울 수준을 높이고, 1 차와 2 차시기에 또래관계의 형성은 우울 수준의 감소에 영향을 미쳐 또래관계 
의 조절효과를 제시하였다. 또, 초등학교 2학년 시기의 우울 등 의 내재화 문제가 초등학교 3학년 시기의 또래피해 문제가 증 가하는 것으로 밝혔다(Leabeater \& Hoglund, 2009). 그러나 공 격성, 또래관계와 우울의 간접효과가 유의하지 않은 것으로 나 타난 본 결과는 이들의 연구결과와 불일치하는 면이 있으나, 내재화 문제는 또래의 사회적 선호나 또래피해 문제를 야기하 지 않는다는 결과(van Lier \& Koot, 2010)와 관련지어 볼 수 있 다. 이러한 불일치한 점은 횡단, 종단적 연구방법의 차이, 거부, 배척, 수용, 피해 및 친구 수로 또래관계의 특성을 측정한 점, 그리고 결과변인이 상이한 점에서 기인한 것으로 사료된다.

또, 이들 결과에 의하면 부모에 의한 학대적 양육방식은 아 동의 관계적 욕구와 가치감을 손상시키는 결과를 초래함으로 써 또래와의 관계에서 거부나 소외를 지각하게 하여 아동의 사 회적 상호작용에 영향을 미칠 수 있음을 내포하고 있다. 한편, 애착이론과 사회정보처리이론의 관점에 의하면, 아동은 부모 와의 상호작용에 기초하여 관계에 대한 내적 모델을 학습하고 그들의 또래관계에 이 내적 모델을 적용한다는 점에서 부모양 육의 간접효과를 강조하고 있다. 그러나 부모는 효율적인 양육 을 통해 아동이 주변사람과 관계를 맺도록 적절한 행동의 예를 제시하고, 사회적 기술을 실행할 기회를 제공함으로써 또래관 계를 발전시켜 나가도록 안내하는 직접적인 역할을 한다는 점 도 고려할 필요가 있다(Ladd, Profilet, \& Hart, 1992).

이상의 연구 결과를 통한 연구의 의의는 다음과 같다. 첫째, 학령후기 아동의 학대경험이 학교적응에 미치는 영향에서 단 일의 요인보다는 본 연구에서 선정한 공격성, 우울, 또래관계 및 자아존중감의 다중 매개변수들이 연속적으로 경유하는 경 로를 확인하고 매개변수들의 순차적인 인과적 영향력을 통해 매개적 관계를 밝힌 것이다. 둘째, 공격성, 또래관계, 우울, 자 아존중감은 학대경험과 학교적응의 관계에 다중의 매개요인 이 작용하여 공격성, 우울은 위험요인으로 또래관계, 자아존 중감은 공격성, 우울을 완화하고 학교적응 향상에 기여하는 보호요인으로 작용하는 매개변수들의 특성을 파악한 것이다. 이들 매개변수들의 매개효과는 공격성이 다른 매개변수들에 비해 상대적으로 크고 그 다음으로 우울로 나타나 후기 아동 기의 공격성과 우울에 대한 개입에 있어 또래관계, 자아존중 감을 함께 고려하는 것이 학교적응을 보다 더 촉진할 수 있음 을 확인한 것이다.

지금까지의 논의를 통해 연구의 제한점과 후속 연구를 위한 제언으로 먼저, 본 연구의 분석에 사용된 패널자료의 학대경험 척도는 신체학대, 정서학대 및 언어폭력의 피해 정도를 측정하 는 내용을 아동들이 지각한 것에 의해 자기보고식으로 측정하
였고 적은 수의 문항으로 되어있다는 점을 들 수 있다. 또, 본 연구는 시간의 경과를 고려하지 않은 횡단적 연구방법을 적용 하여 이전의 학대경험을 고려하지 않았기 때문에 학대경험의 지속에 따른 만성적 정도를 고려하지 못한 측면이 있다. Bolger 등(1998)은 종단적 연구를 통해 학대경험 아동 중 일부에서 좋 은 친구관계를 가진 일부 아동은 시간경과에 따라 자아존중감 이 향상되는 것으로 나타남에 따라 학대가 처음 시작된 시기, 학대를 경험한 발달 시기, 지속 기간 및 심각성 정도에 따라 학 교적응에 영향을 미치는 매개효과는 다를 수 있을 것이다. 추 후연구에서는 학대경험을 다중 영역으로 분류하여 보호자 면 담, 평가자를 통해 측정함으로써 학대경험이 매개변인에 미치 는 영향력을 심층적으로 파악해보는 것이 요구된다.

다음, 본 연구에서는 학령후기 아동의 또래관계는 아동이 지각하는 또래관계 정도로 측정한 척도이었다. Perkins와 Jones (2004)의 연구에서 위험한 행동을 하는 친구가 있는 것은 학대 를 경험한 청소년의 적응 수준이 감소한 것과는 대조적으로 성 장지향적 행동을 하는 비율이 높은 학대를 경험한 청소년은 친 사회적 행동을 하는 친구와 관계를 맺는 것으로 나타났다. 이 결과는 후기 아동기와 청소년기에 이들의 환경적 맥락이 가정 에서 학교와 또래관계로 확대되면서 또래집단의 규범이 전이 되는 것을 시사한다. 그러나 본 연구에서는 또래관계 척도의 점수가 높을수록 또래관계가 잘 유지되는 정도로 측정하여 또 래관계의 질과 특성이 반영되지 못한 제한점이 있다. 이에 대 한 보완으로 후속연구를 통해 또래관계의 특성을 수용, 거부, 피해 및 친구 유무로 측정하여 우울, 공격성 및 자아존중감에 미치는 영향을 분석해 볼 수 있을 것이다.

끝으로, 본 연구는 횡단연구로 매개효과 검정에 있어 공격 성, 또래관계, 우울 및 자아존중감을 시불변 변수로 분석하였 다. 그러나 아동의 발달과 적응 및 부적응적 행동에 관련되는 이들 변수들이 환경과의 상호작용에 의한 현재와 시간의 경과 에 따른 발달적 산물임을 간과한 측면이 있다. 아동의 학대경 험이 공격성, 또래관계, 우울 및 자아존중감을 순차적으로 경 유하여 학교적응에 영향을 미치는 다중매개효과가 확인됨에 따라 초기 아동기에서 후기 아동기에 걸쳐 시간적 변화를 고려 한 종단적 연구방법을 적용하여 이들 매개변수 간의 상호인과 적 관계의 과정을 알아보는 추후연구가 요구된다. 이를 통해 아동의 발달과 적응적 행동을 촉진하는 보호요인과 적응유연 성의 기능을 확인하는 방향으로 연구를 확장함으로써 아동기 의 발달과 성장을 촉진하고 부적응적 문제를 예방하기 위한 구 체적인 정보제공에 도움이 될 것으로 기대된다. 


\section{Conflict of Interest}

No potential conflict of interest relevant to this article was reported.

\section{References}

\section{In English}

Bolger, K. E., Patterson, C. J., \& Kupersmidt, J. B. (1998). Peer relationships and self-esteem among children who have been maltreated. Child Development, 69(4), 1171-1197. doi:10.1111/j.1467-8624.1998.tb06166.x

Bukowski, W. M., Laursen, B., \& Hoza, B. (2010). The snow effect: Friendship moderates escalations in depressed affect among avoidant and excluded children. Development and Psychopathology, 22(4), 749-757. doi:10.1017/ S095457941000043X

Danielsen, A. G., Samdal, O., Hetland, J., \& Wold, B. (2009). Schoolrelated social support and students' perceived life satisfaction. The Journal of Educational Research, 102(4), 303-318. doi:10.3200/JOER.102.4.303-320

Éthier, L. S., Lemelin, J.-P., \& Lacharité, C. (2004). A longitudinal study of the effects of chronic maltreatment on children's behavioral and emotional problems. Child Abuse and Neglect, 28(12), 1265-1278. doi:10.1016/j.chiabu.2004.07.006

GhorbaniAmir, H., \& AhmadiGatab, T. (2011). The study of relationship between child raising and self-esteem among both male and female students. Procedia-Social and Behavioral Sciences, 30, 2019-2026. doi:10.1016/j.sbspro.2011.10.391

Hayes, A. F. (2013). Introduction to mediation, moderation, and conditional process analysis: A regression-based approach. New York: The Guilford Press.

Hoglund, W. L. G., \& Chisholm, C. A. (2014). Reciprocating risks of peer problems and aggression for children's internalizing problems. Developmental Psychology, 50(2), 586-599. doi:10.1037/a0033617

Ladd, G. W. (2006). Peer rejection, aggressive or withdrawn behavior, and psychological maladjustment from ages 5 to 12: An examination of four predictive models. Child Development, 77(4), 822-846. doi:10.1111/j.1467-8624.2006.00905.x

Ladd, G. W., Profilet, S. M., \& Hart, C. H. (1992). Parents' management of children's peer relations: Facilitating and supervising children's activities in the peer culture. In R. D. Parke \& G. W. Ladd (Eds.), Family-peer relationships: Modes of linkage (pp. 215-253). Hillsdale, NJ: Lawrence Erlbaum.

Leadbeater, B. J., \& Hoglund, W. L. G. (2009). The effects of peer victimization and physical aggression on changes in internalizing from first to third grade. Child Development, 80(3), 843-859. doi:10.1111/j.1467-8624.2009.01301.x

Lilienfeld, S. O. (2003). Comorbidity between and within childhood externalizing and internalizing disorders: Reflections and directions. Journal of Abnormal Child Psychology, 31(3), 285291.

Morrow, M. T., Hubbard, J. A., McAuliffe, M. D., Rubin, R. M., \& Dearing, K. F. (2006). Childhood aggression, depressive symptoms, and peer rejection: The mediational model revisited. International Journal of Behavioral Development, 30(3), 240-248. doi:10.1177/0165025406066757

Moylan, C. A., Herrenkohl, T. I., Sousa, C., Tajima, E. A., Herrenkohl, R. C., \& Russo, M. J. (2010). The effects of child abuse and exposure to domestic violence on adolescent internalizing and externalizing behavior problems. Journal of Family Violence, 25(1), 53-63. doi:10.1007/s10896-009-9269-9

Perkins, D. F., \& Jones, K. R. (2004). Risk behaviors and resiliency within physically abused adolescents. Child Abuse and Neglect, 28, 547-563. doi:10.1016/j.chiabu.2003.12.001

Shen, A. C.-T. (2009). Self-esteem of young adults experiencing interparental violence and child physical maltreatment: Parental and peer relationships as mediators. Journal of Interpersonal Violence, 24(5), 770-794. doi:10.1177/0886260508317188

Shonk, S. M., \& Cicchetti, D. (2001). Maltreatment, competency deficits, and risk for academic and behavioral maladjustment. Developmental Psychology, 37(1), 3-17. doi:10.1037//0012-1649.37.1.3

Soler, L., Kirchner, T., Paretilla, C., \& Forns, M. (2013). Impact of poly-victimization on mental health: The mediator and/ or moderator role of self-esteem. Journal of Interpersonal Violence, 28(13), 2695-2712. doi:10.1177/0886260513487989

Spencer, M. B. (1999). Social culture influence on school adjustment: The application of an identify-focused cultural ecological perspective. Educational Psychologist, 34(1), 4357.

Stirling, J., \& Amaya-Jackson, L. (2008). Understanding the behavioral and emotional consequences of child abuse. Pediatrics, 122(3), 667-673. doi:10.1542/peds.2008-1885

Taussig, H. N., \& Culhane, S. E. (2010). Emotional maltreatment and psychological functioning in preadolescent youth placed in out-of-home care. Journal of Aggression, Maltreatment \& Trauma, 19(1), 52-74. doi:10.1080/10926770903476008

van Lier, P. A. C., \& Koot, H. M. (2010). Developmental cascades of peer relations and symptoms of externalizing and internalizing problems from kindergarten to fourth-grade elementary school. Development and Psychopathology, 22(3), 569-582. doi:10.1017/S0954579410000283

Wood, J. J., McLeod, B. D., Sigman, M., Hwang, W.-C., \& Chu, B. C. (2003). Parenting and childhood anxiety: Theory, empirical 
findings, and future direction. Journal of Psychology and Psychiatry, 44(1), 134-151. doi:10.1111/1469-7610.00106

\section{In Korean}

An, H. J. (2016). The longitudinal analysis about abuse and neglect from parents, adolescents' depression, and school adjustment. Journal of Learner-Centered Curriculum and Instruction, 116(2), 475-493. doi:10.22251/jlcci.2016.16.12.475

An, H. S. (2014). An effect of parental abuse experience on selfesteem among children. Journal of Future Early Childhood Education, 21(1), 185-203.

Bae, B. R. (2015). (SPSS/Amos/LISREL/SmartPLSe uihan) Jojeolhyogwa mit maegaehyogwabunseok [(SPSS/Amos/ LISREL/SmartPLS에 의한) 조절효과 및 매개효과분석]. Seoul: Chungram Publishing Co.

Bae, H. (2010). Impact of abuse experience on children's school adjustment: Mediating factors of resilience. Journal of Korea Council for Children \& Rights, 14(2), 193-217.

Chang, C.-J., \& Yang, H.-W. (2007). Structural equation modeling about parents-child relationship, children's depression, aggression, and school adjustment. Studies on Korean Youth, 18(2), 5-29.

Cho, M., Kim, C., \& Song, H. J. (2014). The structural relationship and latent mean analysis of gender among abuse, peer attachment, self-respect, depression and aggression for middle school students. Journal of Adolescent Welfare, 16(2), 29-54.

Chung, I.-J. (2008). Developmental pathways from child abuse to peer rejection. Korean Journal of Child Studies, 29(4), 79-95.

Hwang, M. J., \& Kim, Y. H. (2018). The mediating effect of ambivalence toward emotional expression in relationships between perceived parenting attitudes and peer relationships in children. Korean Journal of Child Studies, 39(5), 17-29. doi:10.5723/kjcs.2018.39.5.17

Jo, E. J. (2012). A study on finding protective factors which effect on children's school adjustment from parents' abusecomparison between abused children and normal children. Forum For Youth Culture, 29(1), 138-164.

Kim, C. K., \& Cho, M. K. (2014). The influence of emotional problem on school adjustment of child: In accordance with level of abuse experience. Journal of Emotional \& Behavioral Disorders, 30(4), 267-290.

Kim, D.-K., \& Kim, W.-I. (2015). Relationship between experience of child abuse and adjustment to school life: Mediating effects of positive thinking. Korean Journal of Youth Studies, 22(10), 387-409.

Kim, E. A., \& Bae, M. Y. (2016). Multiple mediation effects of adolescent's social withdrawal and peer relationship on the relation between negative parenting style and life satisfaction. Korean Journal of Youth Studies, 23(9), 155176. doi:10.21509/KJYS.2016.09.23.9.155
Kim, H. G. (2014). The effect of perceived parental abuse and neglect and peer attachment on school life adjustment according to children's gender. Family and Environment Research, 52(1), 11-19. doi:10.6115/fer.2014.52.1.11

Kim, H. G., \& Jo, H. Y. (2016). The effect of child neglect and abuse by parents on school adjustment of school-aged children: The mediating effects of self-awareness and peer attachment. Korean Journal of Childcare and Education, 12(1), 19-36. doi:10.14698/jkcce.2016.12.019

Kim, H.-J., \& Hong, S.-H. (2015). The mediating effects of peer attachment and self-esteem on the relationships between parenting attitude and school adjustment. The Journal of Korea Elementary Education, 26(1), 413-429.

Kim, J., \& Song, S. (2014). The moderating effect of depression on the relationship between attention problems and school adjustment levels in middle school students. Studies on Korean Youth, 25(1), 5-27. doi:10.14816/sky.2014.02.72.05

Kim, J.-C., \& Choi, J.-Y. (2011). The influence of child abuse by parents on child aggression: The mediating effect of self-esteem and victimization. The Journal of Child Education, 20(1), 19-32.

Kim, J. Y. (2014). The effect of children's emotional abuse experience level on the school adjustment: Focused on a moderating effect of their self-esteem. Health and Social Welfare Review, 34(3), 286-316. doi:10.15709/hswr.2014.34.3.286

Kim, M., \& Park, M. S. (2004). A study on the relationship of child abuse to academic achievement. Korean Journal of Child Studies, 25(5), 29-40.

Kim, M. J., \& Doh, H. S. (2001). The Influence of parenting behaviors, marital conflict, and sibling relations on aggression in children. Korean Journal of Child Studies, 22(2), 149-166.

Kim, S., \& Chun, J. S. (2015). The effects of child abuse experience on children's school adjustment: The mediating effects of internalizing and externalizing problems. Journal of Youth Welfare, 17(4), 387-410. doi:10.19034/KAYW.2015.17.4.17

Kim, S., \& Lee, B. J. (2010). A study on the relationship between latent classes of child maltreatment and delinquency in the transition from childhood to adolescence. Journal Korean Council for Children \& Rights, 14(3), 327-353.

Kim, S., Yim, H., \& Chung, I. (2014). The pathways from child maltreatment to interpersonal relationships in middle school. Studies on Korean Youth, 25(4), 5-33. doi:10.14816/ sky.2014.11.75.05

Kim, S. J., \& Chung, I. J. (2013). A longitudinal study of persistent and recency effects of child maltreatment on depression, anxiety and aggression. Journal of the Korean Society of Child Welfare, 43, 1-28.

Kwon, J.-E., Lee, E.-J., \& Nho, C.-R. (2013). Mediating effects of teacher and peer relationship on the association between child abuse and neglect and school performance. Journal of the Korean Society of Child Welfare, 42, 29-54. 
Lee, H. B. (2014). The influence of domestic violence and child abuse internalization and externalization in multicultural families child. The Journal of Welfare and Counseling Education, 3(2), 55-79.

Lee, J.-I., Kim, C.-K., \& Han, E.-S. (2014). A structural analysis of parental attachment, peer attachment, self-efficacy, and school adjustment perceived by elementary school student. The Journal of Elementary Education, 27(4), 345-367.

Lee, K. M., \& Kim, M. S. (2008). A validation study on the school adjustment scale for middle school student. The Korean Journal of School Psychology, 5(1), 27-40.

Lee, L. H. (2014). Easyflow regression analysis. Seoul: Hannarae Publishing Co.

Lee, S.-J., \& Nam, J.-S. (2016). Effects of low self-esteem based on experiences of child abuse on aggressiveness-Targeting juvenile reformatory inmate-. Korean Criminal Psychology Review, 12(3), 87-112.

Lee, Y. A., \& Choi, J. A. (2015). The mediating effect of self-esteem in the relation between parental abuse, neglect and school life adjustment in adolescent. Family and Environment Research, 53(3), 331-339.

Ministry of Health and Welfare. (2018). Child Abuse \& Neglect Korea 2017. Seoul: National Child Protection Agency. Retrieved from National Child Protection Agency of MHW website: http://www.korea1391.go.kr/new/bbs/ board.php?bo_table=report $\& w r \_i d=9870$

Moon, E. S. (2002). An exploratory study on the variables related to adolescents' school adjustment. The Journal of Educational Research \& Development, 23(1), 153-167.

National Youth Policy Institute. (2017). Korean children and youth panel survey [Data file and code book]. Retrieved from NYPI website: http://archive.nypi.re.kr/

Oh, M. S., \& Shim, W. (2014). The effects of academic stress on children's depression: Focusing on moderating effects of self-esteem. Journal of School Social Work, 29, 237-261.

Park, A. (2014). The effect of perceived neglect on children's depressive symptoms: Focusing on mediating effects of self- esteem and social withdrawal. Journal of Adolescent Welfare, 16(4), 397-416.

Park, E. J., \& Choi, M. O. (2014). The relation of abusive parenting to delinquency behaviors and victimization experience among adolescents: Focusing on mediating effects of depression and aggression. Journal of Family Relations, 18(4), 219-238.

Park, K.-W. (2014). The effects of parents' neglect and abuse on the school adjustment in adolescents: The mediating effects of social withdrawal. Korean Journal of Child Studies, 35(1), 1-15. doi:10.5723/KJCS.2014.35.1.1

Park, S., \& Yoon, C. (2013). The effects of personal and family variables on the school adjustment of 6 th and 9th grade Korean students. Studies on Korean Youth, 24(3), 147-169.

Park, Y. J., \& Sung, H. J. (2014). The impact of abuse experience from caregivers on children's school adjustment-Focusing on the mediating effects of depression and aggression-. Journal of the Korean Society of Child Welfare, 46, 85-114.

Shin, H., \& Kim, G. (2014). The impact of family background and developmental factors on school adjustment: A panel analysis of Korean middle school students. Studies on Korean Youth, 25(1), 85-106. doi:10.14816/sky.2014.02.72.85

You, H.-J. (2014). The structural relationship among experience of abuse for early adolescent, depression, aggression, social withdrawal, and mobiile phone dependency: Focusing on gender differences. Journal of Youth Studies, 21(12), 417-446.

\section{ORCID}

Young Ae Lee http://orcid.org/0000-0002-4285-7470

Received December 31, 2018

Revision received February 15, 2019

Accepted March 15, 2019 